\title{
Influence of fineness level and applied agglomeration pressure of peppermint herb (Mentha piperita L.) on the mechanical properties of the obtained product
}

\author{
Urszula Sadowska' ${ }^{*}{ }^{1}$, Andrzej Żabiński ${ }^{l}$, Krzysztof Mudryk ${ }^{l}$ \\ ${ }^{1}$ University of Agriculture in Krakow, Faculty of Production and Power Engineering, Balicka 116 B, 30-149 Krakow, Poland
}

\begin{abstract}
The objective of the conducted study was to evaluate the impact of the pressure agglomeration process of peppermint herb on the mechanical properties of the obtained product. The separated fractions of peppermint with $0.5-2.5$ and $2.5-5 \mathrm{~mm}$ particles were compacted using a hydraulic press Fritz Heckert EU 20, with pressure 50, 100, 150 and $200 \mathrm{MPa}$. A closed matrix with the compression chamber diameter of $15.6 \mathrm{~mm}$ was used. Every time, a 2-g herb sample (corresponding to the weight of tea used for the production of tea bags) was poured into the matrix. Thus, compacted herb in the form of a straight cylinder was obtained. When producing the agglomerate compaction work was determined. Strength tests of the obtained agglomerate were conducted using the MTS Insight 2 testing machine. The density of the produced agglomerate, its compaction level and strength in the Brazilian test was calculated.

The obtained results indicate that the values of the tested parameters increase with the increase of pressure in the tested range, yet differences occur between the tested herb fractions. Typically, the agglomerate produced from $0.5-2.5 \mathrm{~mm}$ fraction is characterized by a greater density, and the higher level of agglomerate compaction is obtained using 2.5-5 $\mathrm{mm}$ herb fraction. The highest strength determined using Brazilian test was determined for agglomerate produced from 0.5-5 mm peppermint herb fraction at 200 MPa pressure and 0.5-2.5 mm fraction using 150 and $200 \mathrm{MPa}$ pressure.
\end{abstract}

\section{Introduction}

For centuries, humans have used herbaceous plants for different aims, focusing primarily on their medicinal properties. Taste or aroma of herbal teas often constitute one of our first childhood memories.

One of the most commonly used herbaceous plant species distributed around the world for the preparation of herbal teas peppermint $[1,2,3,4]$. It typically is sold in loose form(leaf), or portioned, in bags. The present study proposes new form of peppermint tea, where the herb is subjected to the pressure agglomeration process. However, only few medicinal substances possess properties enabling their direct compaction. Yaman et al. [5] believe that the compaction pressure and other parameters of the process shall be selected depending on the compacted material. However, selection of the suitable pressure is not an easy task, as its values change depending on the properties of the processed material [6]. The compaction pressure is one of the most important factors determining obtaining of a product (pellet, blocks) with the desired quality [7]. Koutný et al. [8] state that the main parameters indicating the quality of products obtained through pressure agglomeration, is, above all, the density, as well as their mechanical strength.

The objective of the conducted study was to evaluate the impact of the pressure agglomeration process of peppermint herb on the mechanical properties of the obtained product.

\section{Materials and methods}

\subsection{Plant material}

The study material was dried peppermint herb (Mentha piperita L.) with the moisture of $11 \%$, which is the upper allowable norm for the species in pharmaceutic terms [9]. From the herb, two fractions of peppermint herb (0.5-2.5 mm and 2.5-5 mm) were separated, using LPzE-2e laboratory shaker with the vibration amplitude of $0-2.5 \mathrm{~mm}$ and sieves with square mesh diameter of $0.5 \mathrm{~mm}, 2.5 \mathrm{~mm}$ and $5 \mathrm{~mm}$.

*Corresponding author: urszula.sadowska@ur.krakow.pl 


\subsection{Methods}

\subsubsection{Pressure compaction process of pepper mint herb}

The bulk density for both obtained fractions was established following the NORM PN-ISO 79712:1998 using a $1 \mathrm{dm}^{3}$ vessel.

The separated herb fractions were compacted using a Fritz Heckert EU 20 hydraulic press with computer recording of with a closed matrix equipped with a compression the compaction process and the pressing mechanism chamber diameter of $15.6 \mathrm{~mm}$ and $82 \mathrm{~mm}$ long. During the test, a curve, the socalled compaction characteristics (relationship between the compaction force and cylinder displacement) was recorded, which was the basis for determination of the process' parameters. Based on presented data, it was possible to determine the compaction process work, defined as the area under the curve. The head travel speed during compaction was $10 \mathrm{~mm} \cdot \mathrm{min}^{-1}$. The process was being carried out at ambient temperature.

The following compaction pressures were used: 50, 100, 150 and $200 \mathrm{MPa}$. Every time, the 2-g weighed herb sample (corresponding to the weight of tea used for the production of tea bags) was manually poured into the matrix. As a result of the process, herb compacted into the form of a straight cylinder was obtained.

\subsubsection{Strength tests}

The study of mechanical strength of compacted peppermint herb with the shape of straight cylinder included determination of tensile strength using Brazilian test method. In this method, a cylindrical sample is subjected to a compacting load along the diameter, thus the other name for the method is the disk test. Such types of load result in sample destruction when the tensile strength is exceeded, in the perpendicular direction to the plane of symmetry containing the direction of the load [10]. This method is commonly used to assess the mechanical properties of cylinder-shaped brittle blocks [11]. The obtained agglomerates were subjected to the disk test using a MTS Insight 2 test machine. The compaction process was conducted until cracks beginning in the central portion of the cylinder, spreading along the vertical axis became visible to the naked eye (Fig. 1).

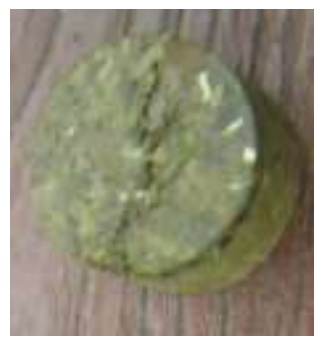

Fig. 1. Example appearance of agglomerate subjected to Brazilian test
Tensile strength during radial compaction was calculated based on the following formula $[12,13]$.

$$
\sigma_{n}=2 \cdot F n \cdot(\pi \cdot d \cdot l)^{-1}
$$

Where:

$\sigma_{n}$ - tensile strength (MPa)

$\mathrm{Fn}$ - agglomerate destructive force $(\mathrm{N})$,

$d$ - compacted sample diameter $(\mathrm{m})$,

$l$-agglomerate length $(\mathrm{m})$.

Moreover, we measured length, diameter and weight of the obtained agglomerate in order to calculate their density in $\mathrm{g} \cdot \mathrm{cm}^{-3}$. The measurements were conducted in 20 repetitions for each combination.

The agglomerate compaction level was also determined, as the multiplication factor of volume decrease, following the methodology presented by Skonecki et al. [14] according to the following formula:

$$
S_{z a}=\rho_{a l} \cdot \rho_{n}^{-1}
$$

Where:

$S_{z a}$ - agglomerate compaction level

$\rho_{a l}-$ agglomerate density after 48 hours of storage $\left(\mathrm{g} \cdot \mathrm{cm}^{-3}\right)$

$\rho_{n}$ - initial material density in the compression chamber (bulk density) $\left(\mathrm{g} \cdot \mathrm{cm}^{-3}\right)$.

After the agglomeration process, the total compaction work was calculated using the registered compaction curves.

Examples of registered courses of the compaction process are presented in Fig. 2.

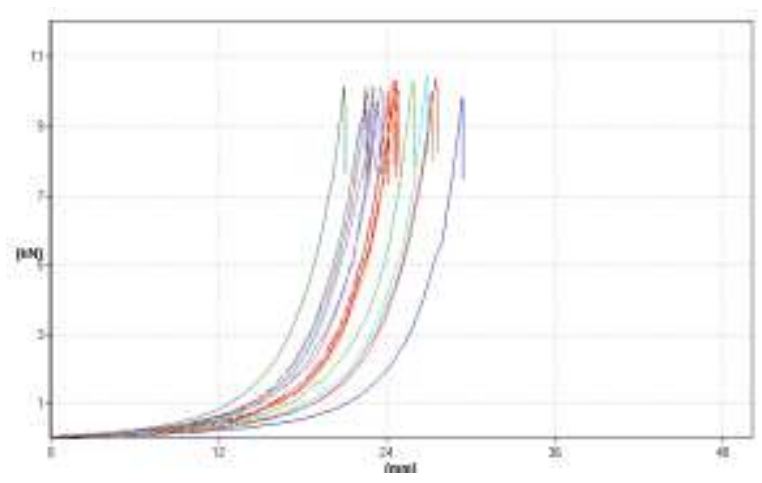

Fig. 2. Selected courses of peppermint herb compaction process

\subsection{Statistical analysis}

Arithmetic means and standard deviations (SD) were calculated for the obtained results. Statistical analysis was performed using the Statistica 10.0 software (Stat Soft, Inc., Tulsa, Oklahoma USA). Multidirectional variance analysis was used. The significance of differences was evaluated using Duncan test at the significance level of $\mathrm{p}=0.05$, and the results were considerably below the level of 
$\mathrm{p}<0.05$. Linear regression models were constructed using Microsoft Excel software for the relationship of the compaction work and the applied pressure.

\section{Study results}

The obtained results of agglomerate strength measurement with the use of the Brazilian test method are presented in Table 1. A significant influence of the applied pressure as well as the separated peppermint herb fraction on its tensile strength was observed. However, a relationship between the applied pressure and separated fraction of peppermint herb was found. According to the Brazilian test, higher strength characterized the agglomerate produced from $0.5-2.5 \mathrm{~mm}$ fraction at pressure 50 and $150 \mathrm{MPa}$ as compared to the same pressures for 2.5-5 mm fraction. The phenomenon of higher susceptibility to cracking of agglomerates produced from materials with lower fineness level is reported by Olsson [15].

The highest strength characterized the agglomerate produced at $200 \mathrm{MPa}$ pressure, independently of fraction and $150 \mathrm{MPa}$ only for 0.5 $2.5 \mathrm{~mm}$ fraction. It can be expected that in the case of the thicker fraction of the herb, empty microspaces could occur between agglomerate particles. The study of Sadowska et al. [16] regarding the grind ability of peppermint agglomerate in a kinetic test also indicate the occurrence of general tendency to improve the mechanical strength of the product when higher pressure is used in the compaction process. However, when subjecting the results of both tests to a comparative analysis, it was observed, that the agglomerate produced from the smaller herb fraction (particularly with lower pressure levels) exhibits better strength parameters in the Brazilian test, whereas in the kinetic test (where its grind ability was tested) it produces inferior results. This phenomenon can be explained by the mechanical wedging-out of the particles, which takes place during compaction of components in the agglomeration process, and then easier separation of the finer particles, due to the limited contact surface of the particles, especially those, which are located on the margins of the product.

Table 1. Values of the Brazilian test of agglomerate produced from different peppermint herb fractions at different pressures

\begin{tabular}{|c|c|c|}
\hline $\begin{array}{c}\text { Fraction } \\
(\mathbf{m m})\end{array}$ & $\begin{array}{c}\text { Pressure } \\
\mathbf{( M P a})\end{array}$ & $\begin{array}{c}\text { Brazilian test } \\
\mathbf{( M P a})\end{array}$ \\
\hline \multirow{3}{*}{$0,5-2,5$} & 50 & $0,443 \pm 0,078 \mathrm{~b}^{*}$ \\
\cline { 2 - 3 } & 100 & $0,938 \pm 0,118 \mathrm{c}$ \\
\cline { 2 - 3 } & 150 & $1,238 \pm 0,052 \mathrm{e}$ \\
\cline { 2 - 3 } & 200 & $1,191 \pm 0,084 \mathrm{e}$ \\
\hline \multirow{2}{*}{$2,5-5,0$} & 50 & $0,384 \pm 0,066 \mathrm{a}$ \\
\cline { 2 - 3 } & 100 & $0,921 \pm 0,093 \mathrm{c}$ \\
\hline
\end{tabular}

\begin{tabular}{|l|l|l|}
\hline & 150 & $1,129 \pm 0,063 \mathrm{~d}$ \\
\cline { 2 - 3 } & 200 & $1,240 \pm 0,070 \mathrm{e}$ \\
\hline
\end{tabular}

*a, b, c ,d, e, - homogenous groups according to Duncan test, $\mathrm{p}=0.05$

Results of the study regarding the density of the obtained agglomerate are presented in tab. 2. An increase of the agglomerate density was observed along with the increase of pressure applied in the experiment. Similar relationships are provided in Skonecki et al. [17]. Typically higher density characterized agglomerate produced from the finer herb fraction. The relationship for different substrates are confirmed by Mani et al. [18], Mani et al. [7], and Carone et al. [19]. However, in the presented study an influence of the applied pressure and herb fraction and the obtained agglomerate density was observed. The obtained results indicate that at $200 \mathrm{MPa}$ pressure the fineness level of peppermint herb no longer influences the density of the produced agglomerate.

Table 2. Agglomerate density depending on the used pressure and separated herb fraction

\begin{tabular}{|c|c|c|}
\hline $\begin{array}{c}\text { Fraction } \\
(\mathbf{m m})\end{array}$ & $\begin{array}{c}\text { Pressure } \\
\mathbf{( M P a})\end{array}$ & $\begin{array}{c}\text { Agglomerate } \\
\text { density }\left(\mathbf{g} \cdot \mathbf{c m}^{-\mathbf{3}} \mathbf{)}\right.\end{array}$ \\
\hline \multirow{3}{*}{$0,5-2,5$} & 50 & $0,805 \pm 0,032 \mathrm{~B}^{\mathbf{*}}$ \\
\cline { 2 - 3 } & 100 & $0,985 \pm 0,025 \mathrm{C}$ \\
\cline { 2 - 3 } & 150 & $1,052 \pm 0,010 \mathrm{E}$ \\
\cline { 2 - 3 } & 200 & $1,073 \pm 0,011 \mathrm{~F}$ \\
\hline \multirow{3}{*}{$2,5-5,0$} & 50 & $0,769 \pm 0,024 \mathrm{~A}$ \\
\cline { 2 - 3 } & 100 & $0,973 \pm 0,023 \mathrm{C}$ \\
\cline { 2 - 3 } & 150 & $1,037 \pm 0,008 \mathrm{D}$ \\
\cline { 2 - 3 } & 200 & $1,066 \pm 0,010 \mathrm{~F}$ \\
\hline
\end{tabular}

* A, B, C, D, E, F - homogenous groups for agglomerate density according to Duncan test, $\mathrm{p}=0.05$

Changes in the agglomerate density confirm results of its compaction level (Table 3). Analysis of the parameter indicated its increased value along the increase of compaction pressure. The relationship for different substrates are confirmed by Kulig et al. [20]. It also depended on the used material fraction, attaining higher values at lower fineness level of the material and equal pressure for each fraction. This relationship appears to be logical, as the material is characterized by lower density also in the bulk form. Such high level of compaction indirectly explains the possible savings of the storage and transporting spaces which can be generated using the agglomeration process.

Table 3. Agglomerate compaction level depending on the used pressure and separated herb fraction

\begin{tabular}{|c|c|c|}
\hline $\begin{array}{c}\text { Fraction } \\
(\mathrm{mm})\end{array}$ & $\begin{array}{c}\text { Pressure } \\
(\mathrm{MPa})\end{array}$ & $\begin{array}{c}\text { Agglomerate } \\
\text { compaction level }\end{array}$ \\
\hline
\end{tabular}




\begin{tabular}{|c|c|c|}
\hline \multirow{4}{*}{$0,5-2,5$} & 50 & $6,242 \pm 0,245 \mathrm{a}^{*}$ \\
\cline { 2 - 3 } & 100 & $7,633 \pm 0,193 \mathrm{c}$ \\
\cline { 2 - 3 } & 150 & $8,156 \pm 0,079 \mathrm{~d}$ \\
\cline { 2 - 3 } & 200 & $8,317 \pm 0,086 \mathrm{e}$ \\
\hline \multirow{3}{*}{$2,5-5,0$} & 50 & $7,124 \pm 0,224 \mathrm{~b}$ \\
\cline { 2 - 3 } & 100 & $9,006 \pm 0,213 \mathrm{f}$ \\
\cline { 2 - 3 } & 150 & $9,605 \pm 0,074 \mathrm{~g}$ \\
\cline { 2 - 3 } & 200 & $9,869 \pm 0,096 \mathrm{~h}$ \\
\hline
\end{tabular}

*a, b, c, d, e, f, g, h - homogenous groups for the compaction level according to Duncan test, $\mathrm{p}=0.05$

Strength parameters of the obtained product shall also be considered in terms of the workload incurred to obtain them. The presented study demonstrated that the level of applied pressure influences the values of compaction work. The total compaction work increased with the increase of pressure value (Table 4). In the majority of cases, no statistically significant differences occurred between the peppermint herb fractions used in the study. Only in the case of the applied pressure of $200 \mathrm{MPa}$ slightly higher values were observed for the finer fraction.

Table 4. Values of compaction work depending on the applied pressure and peppermint herb fraction

\begin{tabular}{|c|c|c|}
\hline $\begin{array}{c}\text { Fraction } \\
(\mathbf{m m})\end{array}$ & $\begin{array}{c}\text { Pressure } \\
\mathbf{( M P a})\end{array}$ & $\begin{array}{c}\text { Total compaction } \\
\text { work }(\mathbf{J})\end{array}$ \\
\hline \multirow{3}{*}{$0,5-2,5$} & 50 & $41,612 \pm 1,788 \mathrm{a}^{*}$ \\
\cline { 2 - 3 } & 100 & $60,464 \pm 2,524 \mathrm{~b}$ \\
\cline { 2 - 3 } & 150 & $78,730 \pm 3,522 \mathrm{c}$ \\
\cline { 2 - 3 } $2,5-5,0$ & 200 & $94,432 \pm 4,493 \mathrm{e}$ \\
\cline { 2 - 3 } & 50 & $41,866 \pm 1,960 \mathrm{a}$ \\
\cline { 2 - 3 } & 100 & $61,908 \pm 2,501 \mathrm{~b}$ \\
\cline { 2 - 3 } & 150 & $78,817 \pm 1,895 \mathrm{c}$ \\
\hline \multirow{3}{*}{} & 200 & $92,621 \pm 2,597 \mathrm{~d}$ \\
\hline
\end{tabular}

*a, b, c, d, e - homogenous groups according to Duncan test, $\mathrm{p}=0.05$

Regression analysis demonstrated that the relationships of the applied agglomeration pressure and values of compaction work can be presented with linear equations. Results of the conducted analysis, with regression equations explaining these relationships are presented in the following charts (Figs. 3-4).

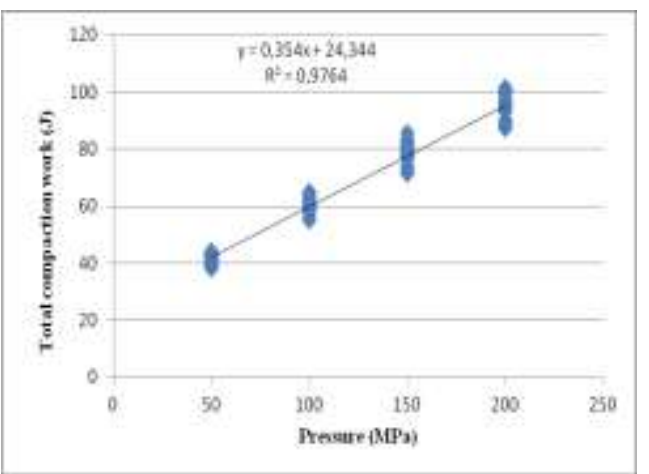

Fig. 3. Relationship between agglomeration pressure and the total compaction work of peppermint herb with fraction $0.5-2.5 \mathrm{~mm}$

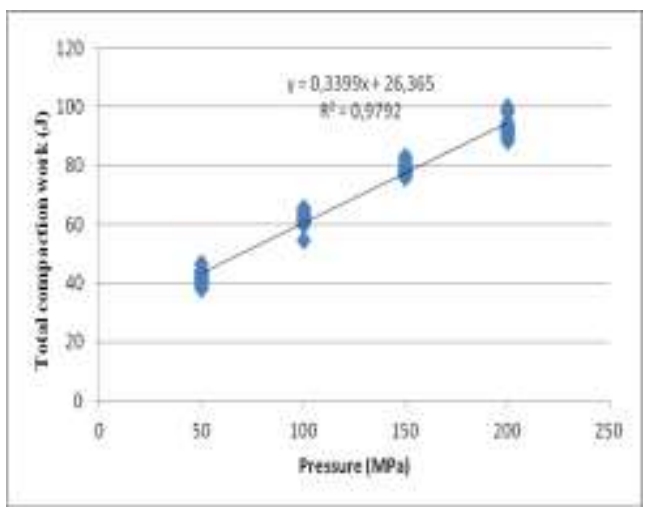

Fig. 4. Relationship between agglomeration pressure and the total compaction work of peppermint herb with fraction 2.5-5.0 $\mathrm{mm}$

High matching index for the linear regression function to the empirical data was demonstrated. In the case of both peppermint herb fractions the coefficient of determination was approx. 0.98.

\section{Conclusions}

1. It was determined that the mechanical strength of peppermint agglomerates depends on the pressure applied during compaction process as well as the fineness level of peppermint herb. Increase of the applied pressure in the range from 50 to $200 \mathrm{MPa}$ results in increased strength of the agglomerate measured with Brazilian test, produced from 0.5-2.5 $\mathrm{mm}$ fraction by approx. $269 \%$, whereas for $2.5-5.0$ $\mathrm{mm}$ fraction by approx. $323 \%$. In the tested pressure range, an increase in the density of agglomerate from the finer herb fraction occurs by approx. $133 \%$, whereas the thicker fraction about $139 \%$.

2. The work necessary to compact the tested peppermint herb fractions depends on the applied agglomeration pressure. Along with the increased pressure in the range $50-200 \mathrm{MPa}$, the workload necessary to compact the material to the form of agglomerate are increased twofold. Strict relationships between agglomeration pressure and the work value for individual peppermint herb fractions were found. 
3. An analysis of the obtained compaction work values, agglomerate density as well as the results of the Brazilian test allows to conclude that the favorable solution for $0.5-2.5 \mathrm{~mm}$ fraction is production of agglomerate at $150 \mathrm{MPa}$ pressure, since as a result it is characterized by high mechanical strength, acceptable density, and the incurred workload is lower than in the case of subsequent pressure used in the experiment. On the other hand, study results regarding 2.5-5.0 mm fraction indicate, that obtaining agglomerates with the highest density and mechanical strength requires the use of $200 \mathrm{MPa}$ pressure.

\section{Acknowledgements}

This research was financed by Ministry of Science and Higher Education of the Republic of Poland.

\section{References}

1. I. Salamon., P. Labun, Herba Pol, 55 (1), (2009)

2. K. Pytlakowska, A. Kita, P. Janoska, M. Połowniak, V. Kozik, Food Chem. 135, (2012)

3. A. Szymczycha-Madeja, M. Welna, W. Zyrnicki, J. Braz. Chem. Soc., 24 (5), (2013)

4. A. de Sousa Barros, S.M. de Morais, P. A. T. Ferreira, Í. G. P. Vieira, A. A.Craveiro, R. O. Fontenelle dos Santos, J. E. S. A. de Menezes, F. W. F. da Silva, H. A.de Sousa. IND CROP PROD, 76, (2015)

5. S. Yaman, M. Sahan, H. Haykiri-Acma, K. Sesen, S. Kucukbayrak, Fuel Process Technol, 68, (2000)

6. R. Hejft, Ciśnieniowa aglomeracja materiatów roślinnych (Biblioteka Problemów Eksploatacji. ITE Radom 2002) ISDN 83-7204-251-9

7. S. Mani, L. G. Tabil, S. Sokhansanj, Biomass Bioenergy, 30 (2006)
8. R. Koutný, B. Čechová, P. Hutla, P. Jevič, Res. Agricul. Eng., 53 (2) (2007)

9. European Pharmacopoeia 6.0, Determination of Essential Oils in Herbal Drugs, 2.8.12, (2008) 251-252

10. J. Mańkowski, P. Ciężkowski, Zeszyty Naukowe Instytutu Pojazdów, 3 (89) (2012)

11. J.R.C. Proveti, G. Michot, INT J FRACTURE, 139, (2006)

12. Y. Li, D. Wu, J. Zhang, L. Chang, D. Wu, Z. Fang, Y. Shi, Powder Technol. 113, (2000)

13. G. Ruiz, M. Ortiz, A. Pandolfi, Int. J. Numer. Meth. Engng. 48, (2000)

14. S. Skonecki, , J. Laskowski, R.Kulig, G. Łysiak, Acta Agroph. 20 (1), (2013)

15. M. Olsson, Wood pellets as low-emitting residential biofuel. Thesis for the degree of licentiate of engineering, Chalmers University of Technology, Gothenburg, Sweden; (2002) http://www.virtualmaze.co.in/sample/Biofuels $\% 20$ Info/Rhombus\%20Power\%20\%20biodiesel/5787.pdf dst 25.08.17

16. U. Sadowska, A. Żabinski, A.Szumny, K. Dziadek, IND CROP PROD, Volume 94, (2016)

17. S. Skonecki, R. Kulig, G. Łysiak, R. Różyło, M. Wójcik, Acta Agroph., 24 (2), (2017)

18. S. Mani, L. G. Tabil, S. Sokhansanj, Evaluation of compaction equations applied to four biomass species. CBE, 46(3), (2004)

19. M.T. Carone, A. Pantaleo, A.Pellerano, Biomass and Bioenergy, 30, (2010)

20. R. Kulig, S. Skonecki, S. Gawłowski, A. Zdybel, G. Łysiak, Acta Sci. Pol., Technica Agraria 12(1-2) (2013) 